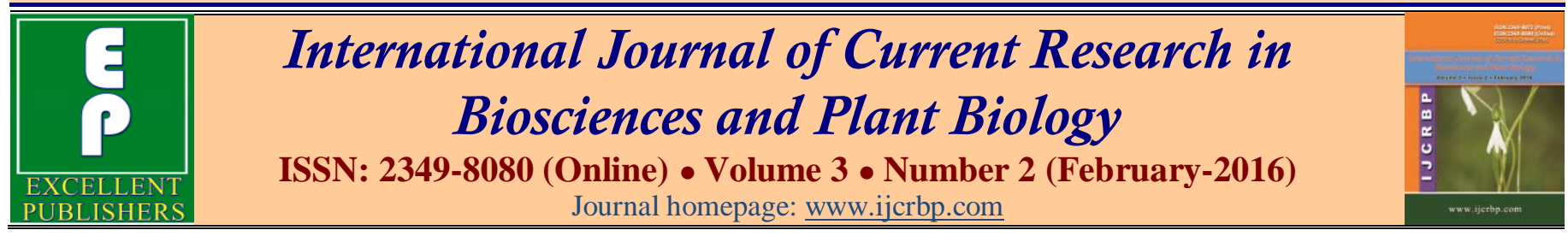

\title{
Supplementation of Virgin Coconut Oil Compared with Copra Oil, Olive Oil and Sunflower Oil on Thrombotic Factors in Rats and In Vitro Platelet Aggregation
}

\author{
Sakunthala Arunima and Thankappan Rajamohan* \\ Department of Biochemistry, University of Kerala, Thiruvananthapuram-695581, Kerala, India \\ *Corresponding author.
}

\begin{abstract}
Virgin coconut oil (VCO) extracted from fresh coconut kernel is becoming very valuable because of its numerous beneficial properties. In the present study, comparative effect of VCO with copra oil (CO), olive oil (OO) and sunflower oil (SFO) on thrombotic factors and platelet aggregation were investigated. Male Sprague-Dawley rats were fed test oils at $8 \%$ level for 45 days along with the synthetic diet. Results demonstrated that compared to $\mathrm{CO}$, a prolonged prothrombin time (PT) and activated partial thromboplastin time (aPTT) were observed in VCO fed rats and was comparable with OO and SFO. Supplementation of VCO reduced the coagulation factors namely factor V, fibrin, fibrinogen and thromboxane B2 levels in plasma compared to those fed $\mathrm{CO}, \mathrm{OO}$ and SFO. Compared to other test oils, platelet aggregating tendency was also reduced in VCO fed rats. The polyphenolic fraction (PF) isolated from VCO inhibited in vitro platelet aggregation induced by ADP compared to PF from other oils. These results indicated that supplementation of VCO has significant antithrombotic effect by inhibiting the activation of platelets and coagulation factors compared to rats fed other test oils.
\end{abstract}

\section{Article Info}

Accepted: 26 January 2016 Available Online: 06 February 2016

\author{
Ke y w o r d s \\ Coronary thrombosis \\ Olive oil \\ Platelet aggregation \\ Polyphenols \\ Thromboxane B2 \\ Thrombotic factor
}

\section{Introduction}

Coronary thrombosis is a major cause of sudden cardiac death, acute myocardial infarction, unstable angina pectoris and silent myocardial ischaemia (Davies and Thomas, 1984; De Wood et al., 1980; Fuster and Chesebro, 1986; Gurfinkel et al., 1994). The thrombogenic state arises when an imbalance exists between procoagulant and profibrinolytic activity (Astrup, 1958; Nossel, 1998). A significant component of thrombogenesis is contributed by platelet and its reactivity (Huo and Ley, 2004). Dietary fat appears to influence both the atherosclerotic and thrombogenic components of coronary heart disease (CHD) (Miller, 1997; Hornstra, 1980). Previous studies have shown that fatty acids affect coagulation of blood (Leray, 2001; Tholstrup, 2003;
Nelson et al., 1997), but the effects of individual fatty acids on haemostasis are still controversial (Hoak, 1997; Knapp, 1997), which depends on both the fatty acid chain length and the degree of saturation (McGregor et al., 1980; Hornstra and Starrenburg, 1973). There is evidence that dietary long-chain saturated fatty acids appear to increase platelet aggregation whereas intake of short and mediumchain fatty acids has been negatively correlated with platelet aggregation (Takachi et al., 2004). Although polyunsaturated fatty acids have been reported to reduce platelet aggregation (Phang et al., 2013; Gao et al., 2013; Moertl et al., 2011), but available evidence on this is equivocal (Mutanen and Freese, 1996; Rand et al., 1988). There are reports which suggest a possible relationship between dietary fat, lipid peroxidation and thrombus formation (Barrowcliffe et al., 1984). 
Apart from fatty acids, antioxidant components present in dietary oil may indirectly inhibit platelets through scavenging of reactive oxygen species (ROS) (Petroni et al., 1994). Previous studies from our laboratory have reported that consumption of virgin coconut oil (VCO) exerts significant antithrombotic effect compared to copra oil (CO) in cholesterol fed rats' In the present study, we investigated the comparative effect of consumption of $\mathrm{VCO}$ with $\mathrm{CO}$, monounsaturated fatty acid (MUFA) rich olive oil (OO) and polyunsaturated fatty acid (PUFA) rich sunflower oil (SFO) on thrombotic factors and platelet aggregation in rats fed normal diet.

\section{Materials and methods}

\section{Chemicals}

Adenosine 5'-diphosphate, factor II, fibrinogen, hemoglobin, and other biochemicals were purchased from Sigma Aldrich Co. (St Louis, MO, USA). All the other chemicals used were of analytical grade.11dehydro TX B2 immunoassay kit was obtained from Cayman Chemical Co. (Ann Arbor, MI, USA).

\section{Extraction of virgin coconut oil and copra oil}

The solid endosperm of mature coconut (West coast tall variety) was crushed, made in to viscous slurry and squeezed through cheese cloth to obtain coconut milk, which was refrigerated for 48 hours, then subjected to mild heating $\left(50^{\circ} \mathrm{C}\right)$ in a thermostat oven. The obtained VCO filtered through cheese cloth was used for the present study (Nevin and Rajamohan, 2004). CO was extracted from coconut meat, which was dried in sunlight continuously for 4 days to remove moisture and the resulting copra was pressed in a mill to obtain $\mathrm{CO}$ (Nevin and Rajamohan, 2008).

\section{Olive oil and sunflower oil}

Olive oil and sunflower oil were purchased from the local market.

\section{Animals and diet}

Male Sprague-Dawley rats (100 -120 g body weight) bred in our department animal house were used for the study. The animals were individually housed under hygienic conditions in polypropylene cages in a room maintained at an ambient temperature of $25^{\circ} \pm 10^{\circ} \mathrm{C}$ with a $12 \mathrm{~h}$ light and $12 \mathrm{~h}$ dark cycle. The rats were randomly divided into four groups of six rats each. Each rat was given a synthetic diet containing $8 \%$ dietary oils daily for 45 days (Table 1). Experimental groups were as follows: Group I rats given $\mathrm{CO}$, Group II rats given VCO, Group III rats given $\mathrm{OO}$ and Group IV rats given SFO. All the animal cares and procedures were according to the guidelines of Committee for the Purpose of Control and Supervision of Experiments on Animals (CPCSEA), India. The entire experimental protocol was approved by Institutional Animal Ethics Committee (IAEC), University of Kerala. Food intake was monitored routinely and body weight was determined weekly. After 45 days, animals were fasted overnight and sacrificed by thiopentone sodium injection $(>40 \mathrm{mg}$ per $\mathrm{kg}$ body weight) and the blood was collected for various estimations.

Table 1. Formulation of synthetic diet.

\begin{tabular}{lllll}
\hline Ingredients $^{\text {a }}$ & Group I & Group II & Group III & Group IV \\
\hline Corn starch & 71 & 71 & 71 & 71 \\
Casein & 16 & 16 & 16 & 16 \\
Copra oil & 8 & -- & -- & -- \\
Virgin coconut oil & -- & -- & -- & -- \\
Olive oil & -- & -- & -- & 8 \\
Sunflower oil & -- & -- & 4 & 4 \\
Salt mixture & 4 & 1 & 1 & 1 \\
Vitamin mixture & 1 & & & \\
\hline
\end{tabular}

${ }^{\mathrm{a}} \mathrm{g}$ per $100 \mathrm{~g}$ wet weight.

\section{Biochemical investigation}

Citrated plasma was used for the determination of coagulation parameters viz., prothrombin time, activated partial thromboplastin time, fibrinogen, fibrin, factor $\mathrm{V}$ and 11-dehydro thromboxane B2. Prothrombin time (PT) was estimated using liquiplastin kit from Tulip Diagnostics (P) Ltd, Goa, India (Hull et al., 1982). Activated partial thromboplastin time (aPTT) was estimated using Liquicelin kit from Tulip Diagnostics (P) Ltd, Goa, India (Hoffmann 
and Meulendijk, 1978). Citrated plasma was diluted with 2 $\mathrm{mL}$ of isotonic saline and from this fibrin was estimated according to the method described by King and Wootton (1959). Plasma fibrinogen levels were estimated as described by Clauss (1957) using fibrinogen kit from Tulip Diagnostics (P) Ltd, Goa, India. Factor V was assayed by the method of Daniel (1955). The concentration of 11dehydro thromboxane B2 in plasma was determined by EIA kit purchased from Cayman Chemical Co.USA (Takasaki, 1991).The absorbance was read at $412 \mathrm{~nm}$ and concentration of each sample was obtained from the standard curve.

\section{Platelet preparation and platelet aggregation test}

Blood was collected in anticoagulant solution $(2.4 \%$ sodium citrate, $1.5 \%$ citric acid and $1.8 \%$ dextrose). The ratio of the blood to anticoagulant solution was approximately 5:1 and the platelet rich plasma (PRP) was separated by centrifugation at $1850 \mathrm{rpm}$ for 7 minutes. PRP was centrifuged at $4500 \mathrm{rpm}$ for 18 minute to sediment the platelets (Chopra, 1999). The platelet sediment was dispersed in washing buffer composed of $113 \mathrm{mM} \mathrm{NaCl}, 4.3 \mathrm{mM} \mathrm{KH} \mathrm{PO}_{4}, 4.3 \mathrm{mM} \mathrm{Na} \mathrm{HPO}_{4}$, $24.44 \mathrm{mM} \mathrm{NaH} \mathrm{PO}_{4}$ and $5.5 \mathrm{mM}$ dextrose (pH 6.5) and the platelets were collected after centrifugation at $900 \mathrm{~g}$ for 10 minutes. The platelet aggregating activity was measured by spectrophotometric method as described by Joseph et al. (2005).

\section{Platelet aggregation in vitro}

In vitro platelet aggregation was performed by the method of Duttaroy and Jorgensen (2004). Polyphenols from test oils were extracted according to the method described previously (Arunima and Rajamohan, 2013). $250 \mu \mathrm{L}$ of platelet suspension was incubated with $50 \mu \mathrm{g}$ of polyphenol fraction isolated from test oils and allowed to stand for 3 minutes. Absorbance of the sample and control were measured at $600 \mathrm{~nm}$ immediately after the addition of agonist (10 $\mu \mathrm{M}$ ADP) and at 120 minutes in a spectrophotometer. The values were expressed as percentage aggregation.

\section{Statistical analysis}

Statistical differences were determined using one way ANOVA followed by Duncan's, post-hoc test to identify the differences using SPSS 11.5 (SPSS Inc., Chicago IL, USA). Differences of $p<0.05$ were considered to be significant. Data are reported as mean \pm SEM unless otherwise stated.

\section{Results}

\section{Effect of VCO on blood coagulation parameters}

Fig. 1 summarizes the levels of prothrombin time (PT) and activated partial thromboplastin time (aPTT) in rats fed test oils. A prolonged PT and aPTT were observed in VCO fed rats when compared to those fed CO. But no significant difference in PT and aPTT were observed among rats fed VCO, OO and SFO. VCO supplementation significantly $(p<0.05)$ decreased the factor $\mathrm{V}$ levels when compared to rats fed other test oils. Factor V levels were also significantly $(p<0.05)$ decreased in $\mathrm{CO}$ fed rats in comparison to those fed $\mathrm{OO}$ and SFO. But supplementation of SFO increased the factor V levels than $\mathrm{OO}$ fed rats (Fig. 2). The concentration of fibrinogen was significantly $(p<0.05)$ decreased in VCO fed rats when compared to other oil fed rats. Fibrinogen levels were also found to be decreased in $\mathrm{CO}$ fed rats compared to those fed $\mathrm{OO}$ and SFO. Rats fed $\mathrm{OO}$ showed increased levels of fibrinogen compared to SFO fed rats. The fibrin levels were also significantly decreased in VCO fed rats compared to other oil fed rats. But there was no significant difference in fibrin levels among rats fed $\mathrm{CO}, \mathrm{OO}$ and SFO (Table 2).

Table 2. Concentration of fibrinogen $(\mathrm{mg} / \mathrm{dL})$ and fibrin $(\mathrm{mg} / \mathrm{dL})$.

\begin{tabular}{lll} 
Groups & Fibrinogen & Fibrin \\
I & $273.12 \pm 27.76^{\mathrm{a}}$ & $17.61 \pm 1.6^{\mathrm{a}}$ \\
II & $237.67 \pm 21.69^{\mathrm{b}}$ & $15.38 \pm 1.55^{\mathrm{b}}$ \\
III & $319.68 \pm 29.09^{\mathrm{c}}$ & $19.64 \pm 1.66^{\mathrm{a}, \mathrm{c}}$ \\
IV & $275.26 \pm 28.38^{\mathrm{d}}$ & $18.32 \pm 1.79^{\mathrm{a}, \mathrm{c}}$ \\
\hline \multicolumn{2}{l}{ Values are mean of six rats \pm SEM, values not sharing a common superscript differs significantly at $p<0.05$. Group I $-8 \%$ CO } \\
fed rats; Group II $-8 \%$ VCO fed rats; Group III $-8 \%$ OO fed rats; Group IV $-8 \%$ SFO fed rats.
\end{tabular}




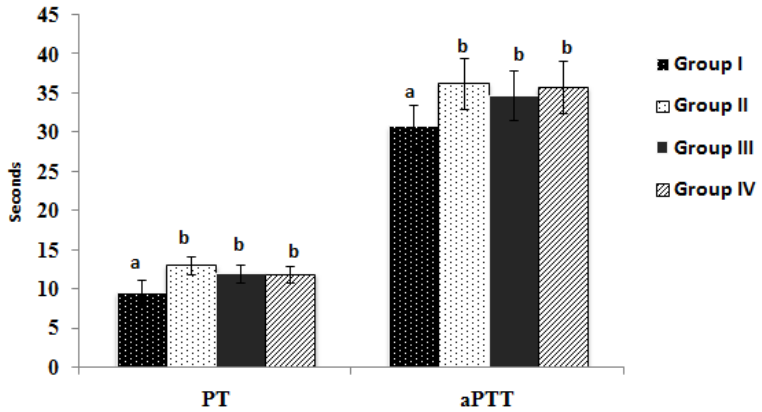

Fig. 1: Prothrombin time and activated partial thromboplastin time. Values are mean of six rats \pm SEM, values not sharing a common superscript differs significantly at $p<0.05$. Group I $8 \%$ CO fed rats; Group II - $8 \%$ VCO fed rats; Group III $-8 \%$ OO fed rats; Group IV $-8 \%$ SFO fed rats.

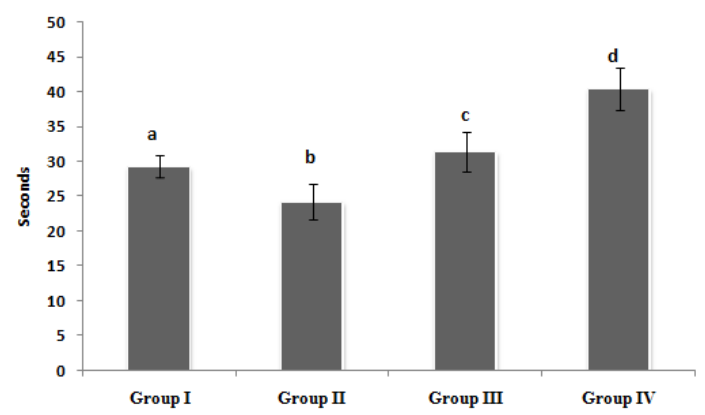

Fig. 2: Concentration of factor V. Values are mean of six rats \pm SEM, values not sharing a common superscript differs significantly at $p<0.05$.Group I $-8 \% \mathrm{CO}$ fed rats; Group II $8 \%$ VCO fed rats; Group III $-8 \%$ OO fed rats; Group IV - $8 \%$ SFO fed rats.

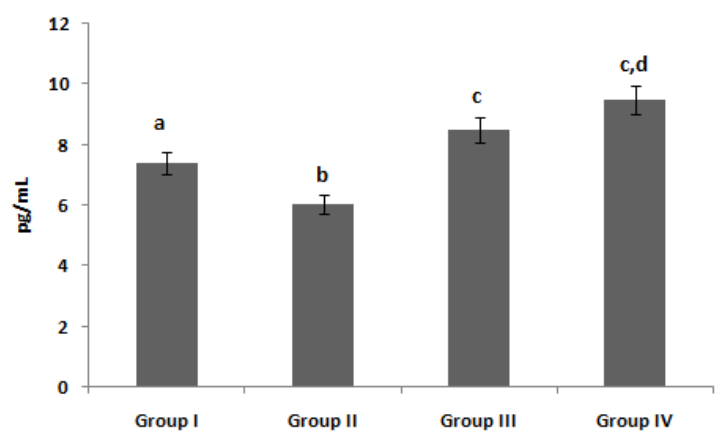

Fig. 3: Concentration of 11-dehydro TX B2 in plasma. Values are mean of six rats \pm SEM, values not sharing a common superscript differs significantly at $p<0.05$. Group I $-8 \% \mathrm{CO}$ fed rats; Group II $-8 \%$ VCO fed rats; Group III $-8 \%$ OO fed rats; Group IV $-8 \%$ SFO fed rats.

\section{Effect of VCO on 11-dehydro thromboxane B2 in plasma}

Concentration of 11-dehydro thromboxane B2 (11dehydro TX B2) were significantly $(p<0.05)$ decreased in VCO fed rats compared to those fed other test oils.
Supplementation of CO decreased the 11-dehydro TX B2 levels when compared to rats fed OO and SFO. But there was no significant difference in 11-dehydro TX B2 levels among $\mathrm{OO}$ and SFO fed rats (Fig. 3).

\section{Effect of VCO on platelet aggregation in vivo and in vitro}

The platelet aggregating tendency was significantly lowered in VCO supplementation compared to other oil fed rats (Fig. 4). There was no significant difference in the aggregation tendency among rats fed $\mathrm{CO}$ and SFO. Results from in vitro analysis indicated that polyphenol fraction (PF) extracted from VCO significantly $(p<0.05)$ decreased ADP induced platelet aggregation than other test oils. But there was no significant difference in platelet aggregating tendency among PF isolated from $\mathrm{CO}, \mathrm{OO}$ and SFO (Fig. 5).

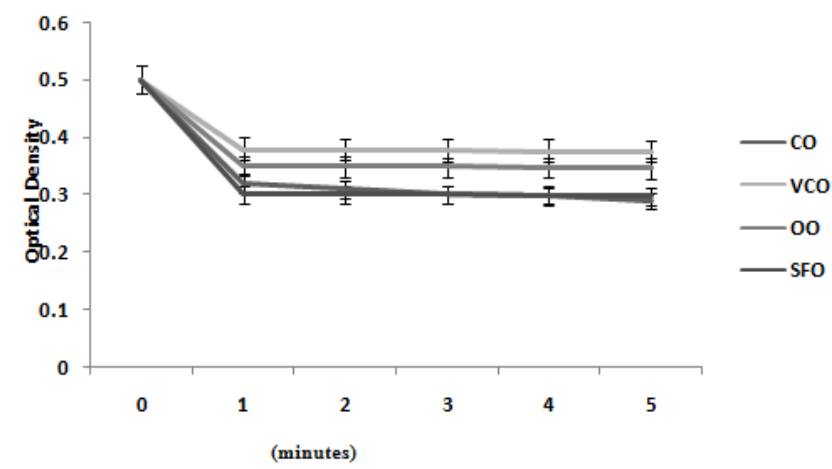

Fig. 4: Platelet aggregation induced by ADP in vivo. Values are mean of six rats \pm SEM, values not sharing a common superscript differs significantly at $p<0.05$.Group I $-8 \% \mathrm{CO}$ fed rats; Group II $-8 \%$ VCO fed rats; Group III $-8 \%$ OO fed rats; Group IV $-8 \%$ SFO fed rats.

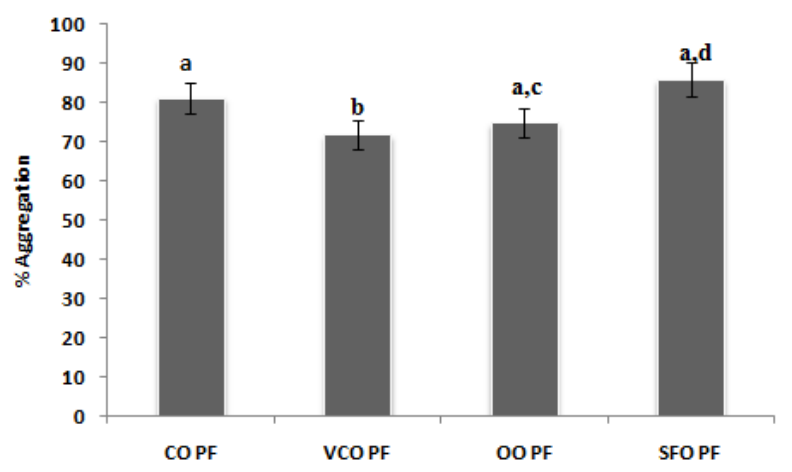

Fig. 5: Platelet aggregation induced by ADP in vitro. Values are mean of six experiments. Values not sharing a common superscript differs significantly at $p<0.05$.Group I-Platelet rich plasma (PRP) + ADP $(10 \mu \mathrm{M})+50 \mu \mathrm{g}$ CO PF; Group II- PRP $+\operatorname{ADP}(10 \mu \mathrm{M})+50 \mu \mathrm{g}$ VCO PF; Group III- PRP + ADP $(10 \mu \mathrm{M})+50 \mu \mathrm{g}$ OO PF; Group IV- PRP + ADP $(10 \mu \mathrm{M})+50$ $\mu \mathrm{g}$ SFO PF. 


\section{Discussion}

Results obtained indicate that supplementation of VCO had a significant beneficial effect on blood coagulation factors in rats fed normal diet. PT and the aPTT are global coagulation tests used to assess the coagulation system. PT, which measures the clotting time of plasma in the presence of thromboplastin, was determined to assess the efficiency of extrinsic system, while, aPTT depends on substances normally present in blood for its activity and to assess the intrinsic pathway. Studies suggested that short aPTT probably represent an increase in the procoagulant potential (McKenna et al., 1977) and were associated with an increased risk of thrombosis (Landi et al., 1992; Gallus et al., 1973). In the present study, a prolonged PT and aPTT were observed in VCO fed rats when compared to CO fed rats. Studies revealed that apart from fatty acids, the unsaponifiable components present in dietary oils have a role in regulating the coagulation system. There are reports that polyphenols possess antithrombotic effects, it was evidenced by a prolonged PT and aPTT (Kim et al., 2012). Chemical analysis of the test oils has revealed that VCO by wet processing retains higher amounts of polyphenols and tocopherols than other test oils (Arunima and Rajamohan, 2013). These higher amounts of polyphenols present in VCO may prolong the PT and aPTT and which may be one of the reasons for its antithrombotic potential.

The factor V levels were found to be decreased in VCO fed rats compared to other groups. Factor V is a $330-\mathrm{kDa}$ glycoprotein synthesized in the liver and is released in the bloodstream as a single-chain inactive pro-cofactor. After limited proteolysis by thrombin or factor $\mathrm{Xa}$, factor $\mathrm{V}$ is converted to its activated form, factor $\mathrm{Va}$ (Monkovic and Tracy, 1990). The factor Va acts as a non enzymatic cofactor of factor Xa in the conversion of prothrombin to thrombin (Nesheim et al., 1979; Rosing et al., 1980). The lesser levels of factor V observed in VCO fed rats reflects reduced thrombotic risk. Moreover, low levels of both fibrin and fibrinogen observed in VCO fed rats are associated with decreased clotting of the blood. A raised plasma fibrinogen concentration is a powerful predictor of risk of fatal CHD (Miller et al., 1996). Clotting response is enhanced by activated blood platelets and the fibrin formed reinforces the fragile platelet mass to a stabilized thrombus of great pathological significance (Mosesson, 2005). Elevated fibrin concentration, lowered prothrombin time and activated partial thromboplastin time are an indication of hypercoagulability (Curnow et al., 2007; McKenna et al., 1977).
Blood clotting is affected by many substances within our body, which depends on a balance between substances that promote coagulation and those that inhibit it (Lipe and Ornstein, 2011). Thromboxane A2 (TX A2) produced by activated platelets, has prothrombotic properties, stimulating activation of new platelets as well as increasing the platelet aggregation. There are reports that thromboxane-dependent platelet activation enhances cerebral thrombosis (Patrono et al., 1991). Moreover, TX A2 acts as both a vasoconstrictor and platelet activator (Ellis et al., 1976). TX A2 has a short half-life in the body and is rapidly hydrolyzed to thromboxane B2 (TX B2).11-dehydro TX B2 is a metabolite of TX B2 with a circulating half-life $\left(\mathrm{t}_{1 / 2}\right)$ of 45 minutes; its measurement in plasma or urine will give a time-integrated indication of TX A2 production (Catella et al., 1986). An increased production of TX B2 might be contributory to thrombosis (Saldeen et al., 1983). Our results revealed significant decrease in 11-dehydro TX B2 levels in VCO fed rats as compared to those fed other oils. There are reports that saturated fats have an inhibitory effect on TX B2 production (Steel et al., 1990), while, unsaturated fatty acids viz., oleic, linoleic and arachidonic acid enhances the production of TX B2 (Ishitsuka et al., 2004; Muakkassa et al., 1991; Whelan et al., 1993). But supplementation of n-3 PUFA reduces TX B2 production (Vilaseca et al., 1990).

Blood platelets are known to play a role in the regulation of hemostasis and thrombosis (Véricel et al., 2004) and consequently in the major cardiovascular complications (Massberg et al., 2002). Platelet-dependent thrombus formation plays an essential role in the manifestation of ischemic heart syndrome (Meade et al., 1986; Heinrich et al., 1994). Platelets are thought to initiate a series of intricate reactions by adhering to the injured arterial lining, aggregating irreversibly to form a platelet plug, and releasing vasoactive metabolites and hydrolytic enzymes that might in turn alter both the function and structure of the vessel (Colman, 1975). Platelets mediate both thrombotic occlusion of the entire epicardial coronary artery and also accumulate in the microcirculation resulting in impairment of microcirculation and provoking myocardial ischemia during reperfusion (Gawaz, 2004).

Studies suggest that individual saturated fatty acids differently affect platelet aggregation capacity (Fuhrman et al., 1986; Renaud et al., 1986). There are reports that chain length of fatty acids plays an important role in platelet aggregation and the inhibitory effect on platelet aggregation was increased with increase in chain length 
up to C 14 (Kitagawa et al., 1984). Fatty acid analysis of test oils revealed that oil extracted from coconut mostly consists of short and medium chain fatty acids (Arunima and Rajamohan, 2013). In vivo experiments have shown that feeding medium chain triglycerides (MCT) decreases thrombosis formation in rats (Kaunitz, 1986). Intervention studies have shown that increased platelet aggregation was found in linoleic acid enriched diets (Mutanen and Freese, 1996). Apart from fatty acids, polyphenols and tocotrienols are known to inhibit platelet aggregation (De Lange et al., 2007; Qureshi et al., 2011). Chemical analysis of these test oils has revealed that VCO by wet processing contain increased polyphenolic contents $(84 \mathrm{mg} / 100 \mathrm{~g}$ oil), which is significantly $(p<0.05)$ higher than other test oils viz., CO $(64.4 \mathrm{mg} / 100 \mathrm{~g}$ oil), OO (75.63 mg/100 g oil) and SFO $(55 \cdot 26 \mathrm{mg} / 100 \mathrm{~g}$ oil).

HPLC analysis of the phenolic fraction of VCO has revealed the presence of caffeic acid, $p$-coumaric acid, ferulic acid, (+)-catechin hydrate and syringic acid compared with $\mathrm{CO}, \mathrm{OO}$ and SFO (Arunima and Rajamohan, 2013), which may have a synergistic effect on platelet aggregation. In addition, the nonsaponifiable fraction of VCO contains appreciably higher amounts of antioxidants, namely vitamin E $(33.12 \mathrm{mg} / 100 \mathrm{~g}$ oil $)$ and b-carotene (196mg/100 g oil) (Arunima and Rajamohan, 2012). Increased amounts of these nonsaponifible components present in VCO may partly be responsible for the decreased platelet aggregation compared with other oils. The inhibitory effect of VCO on platelet aggregation was confirmed by the in vitro platelet aggregation assay using polyphenol fraction isolated from test oils. A decreased aggregation rate was observed with VCO polyphenols on ADP induced in vitro platelet aggregation.

These results demonstrated that supplementation of VCO have a significant antithrombotic effect compared to those fed $\mathrm{CO}, \mathrm{OO}$ and SFO, which is characterized by an increased fibrinolytic activity as well as decreased rate of platelet aggregation.

\section{Conflict of interest statement}

Authors declare that they have no conflict of interest.

\section{Acknowledgement}

Financial assistance in the form of a research fellowship from the University of Kerala (grant number 5825/2009) to $\mathrm{S}$. Arunima is gratefully acknowledged; the University of Kerala had no role in the design, analysis or writing of this article. All authors read and approved the final manuscript. The authors declare that there are no real or perceived conflicts of interest.

\section{References}

Arunima, S., Rajamohan, T., 2012. Virgin coconut oil improves hepatic lipid metabolism in rats compared with copra oil, olive oil and sunflower oil. Indian. J. Exp. Biol. 50(11), 802-809.

Arunima, S., Rajamohan, T., 2013. Effect of virgin coconut oil enriched diet on the antioxidant status and paraoxonase 1 activity in ameliorating the oxidative stress in rats - a comparative study. Food Funct. 4(9), 1402-1409.

Astrup, T., 1958. The haemostatic balance. Thrombos. Diath. Haemorrh. 2(3-4), 347-357.

Barrowcliffe, T.W., Gray, E., Kerry, P.J. and Gutteridge, J.M., 1984. Triglyceride-rich lipoproteins are responsible for thrombin generation induced by lipid peroxides. Thromb. Haemost. 52(1), 7-10.

Catella, F., Healy, D., Lawson, J.A., Fitzgerald, G.A., 1986. 11-Dehydrothromboxane B2: A quantitative index of thromboxane A2 formation in the human circulation. Proc. Natl. Acad. Sci. USA. 83 (16), 5861-5865.

Chopra, G., Chhaya, S.U., Bharucha, Z.S., Kane, S.V., 1999. Achieving quality of randomdonor platelet concentrates. Indian. J. Hemat. Blood. Transf. 17(3), 54-58.

Clauss, A., 1957. Rapid physiological coagulation method in determination of fibrinogen. Acta. Haematol. 17 (4), 237-246.

Colman, R.W., 1975. Platelet aggregation and thrombotic vascular disease. Ann. Intern. Med. 82(6), 839.

Curnow, J.L., Morel-Kopp, M.C., Roddie, C., Aboud, M., Ward, C.M., 2007. Reduced fibrinolysis and increased fibrin generation can be detected in hypercoagulable patients using the overall hemostatic potential assay. J. Thromb. Haemost. 5(3), 528-534.

Daniel, L.K., 1955. Enzymes in blood clotting. Meth. Enzymol. 2, 139-166.

Davies, M.J., Thomas, A., 1984. Thrombosis and acute coronary artery lesions in sudden cardiac ischemic death. N. Engl. J. Med. 310(18), 1137-1140.

De Lange, D.W., Verhoef, S., Gorter, G., Kraaijenhagen, R.J., van de, Wiel, A., Akkerman, J.W., 2007. Polyphenolic grape extract inhibits platelet activation through PECAM1: an explanation for the French paradox. Alcohol. Clin. Exp. Res. 31(8), 1308-1314.

De Wood, M.A., Spores, J., Notske, R., Mouser, L.T., Burroughs, R., Golden, M.S., Lang, H.T., 1980. Prevalence of total coronary occlusion during the early hours of transmural myocardial infarction. N. Engl. J. Med. 303(16), 897-902.

Duttaroy, A.K., Jorgensen, A., 2004. Effects of kiwi fruit consumption on platelet aggregation and plasma lipids in healthy human volunteers. Platelets. 15(5), 287-292. 
Ellis, E.F., Oelz, O., Roberts, L.J., 1976. Coronary arterial smooth muscle contraction by a substance released from platelets: Evidence that it is Thromboxane A2. Science. 193(4258), 1135-1137.

Fuhrman, B., Brook, J.G., Aviram, M., 1986. Increased platelet aggregation during alimentary hyperlipemia in normal and hypertriglyceridemic subjects. Ann. Nutr. Metab. 30(4), 250-260.

Fuster, V., Chesebro, J.H., 1986. Mechanism of unstable angina. N. Engl. J. Med. 315(16), 1023-1025.

Gallus, A.S., Hirsh, J., Gent, M., 1973. Relevance of preoperative and postoperative blood tests to postoperative leg-vein thrombosis. Lancet. 2(7833), 805-809.

Gao, L.G., Cao, J., Mao, Q.X., Lu, X.C., Zhou, X.L., Fan, L., 2013. Influence of omega-3 polyunsaturated fatty acidsupplementation on platelet aggregation in humans: a meta- analysis of randomized controlled trials. Atherosclerosis. 226(2), 328-334.

Gawaz, M., 2004. Role of platelets in coronary thrombosis and reperfusion of ischemic myocardium. Cardiovasc. Res. 61 (3): 498-511.

Gurfinkel, E., Altman, R., Scazziota, A., Rouvier, J., Mautner, B., 1994.Importance of thrombosis and thrombolysis in silent ischaemia: comparison of patients with acute myocardial infarction and unstable angina. Br. Heart J. 71 (2), 151-155.

Heinrich, J., Balleisen, L., Schulte, H., Assmann, G., van de Loo, J., 1994. Fibrinogen and factor VII in the prediction of coronary risk. Results from the PROCAM study in healthy men. Arterioscler. Thromb. 14(1), 54-59.

Hoak, J.C., 1997. Fatty acids in animals: thrombosis and hemostasis. Am. J. Clin. Nutr. 65(5), 1683-1686.

Hoffmann, J.J., Meulendijk, P.N., 1978. Comparison of reagents for determining the activated partial thrombo plastin time. Thromb. Haemost. 39(3), 640-645.

Hornstra, G., 1980. Dietary prevention of coronary heart disease. Effect of dietary fats on arterial thrombosis. Postgrad. Med. J. 56(658), 563-557.

Hornstra, G., Starrenburg, A.V., 1973. Induction of experimental arterial occlusive thrombi in rats. Atherosclerosis. 17(3), 369-382.

Hull, R., Hirsh, J., Jay, R., Carter, C., England, C., Gent, R.N.M., Turpie, A.G.G., McLoughlin, D., Dodd, P., Thomas, M., Raskob, G., Ockelford, P., 1982. Different intensities of oral anticoagulant therapy in the treatment of proximal- vein thrombosis. N. Eng. J. Med. 307(27), 1676-1681.

Huo, Y., Ley, K.F., 2004.Role of Platelets in the development of atherosclerosis. Trend.s Cardiovasc. Med. 14 (1), 18-22.

Ishitsuka, Y., Moriuchi, H., Hatamoto, K., Yang, C., Takase, J., Golbidi, S., Irikura, M., Irie, T., 2004. Involvement of thromboxane A2 (TXA2) in the early stages of oleic acidinduced lung injury and the preventive effect of ozagrel, a TXA2 synthase inhibitor, in guinea-pigs. J. Pharm. Pharmacol. 56 (4),513-520.

Joseph, S.M., George, M.C., Nair, R.J., Senan, P.V., Pillai, D., Sherief, P.M., 2005. Effect of feeding cuttlefish liver oil on immune function, inflammatory response and platelet aggregation in rat. Current. Science. 88(3), 507-510.

Kaunitz, H., 1986. Medium chain triglycerides (MCT) in aging and arteriosclerosis. J.Environ. Pathol. Toxicol. Oncol. 6 (3-4), 115-121.

Kim, D., Ku, S., Bae, J. 2012. Anticoagulant activities of curcumin and its derivative. BMB. Reports. 45(4), 221226. PMID: 22531131.

King, E.J., Wootton, D.P., 1959. Procedures for plasma. In: Microanalysis in Medical Biochemistry (Ed.: J \& A Churchill (L), London. pp.39-40.

Kitagawa, S., Nishitama, H., Kametani, F., 1984. Inhibition of ADP-induced aggregation of bovine platelets by saturated fatty acids and its relation with the change of membrane surface charge. Biochim. Biophys. Acta. 775(2), 197-202.

Knapp, H.R., 1997. Dietary fatty acids in human thrombosis and hemostasis. Am. J. Clin. Nutr. 65(5), 1687-1698.

Landi, G., D'Angelo, A., Boccardi, E., Candelise, L., Mannucci, P. M., Morabito, A., Orazio, E. N., 1992. Venous thromboembolism in acute stroke: prognostic importance of hypercoagulability. Arch. Neurol. 49(3), 279-283.

Leray, C., Wiesel, M.L., Freund, M., Cazenave, J.P., Gachet, C., 2001. Long-chain n-3 fatty acids specifically affect rat coagulation factors dependent on vitamin $\mathrm{K}$ : relation to peroxidative stress. Arterioscler. Thromb. Vasc. Biol. 21 (3), 459-465.

Lipe, B., Ornstein, D.L., 2011. Deficiencies of natural anticoagulants, protein $\mathrm{C}$, protein $\mathrm{S}$, and antithrombin. Circulation. 124(14), e365-e368.

Massberg, S., Brand, K., Gruner, S., Page, S., Muller, E., Muller, I., Bergmeier, W., Richter, T., Lorenz, M., Konrad, I., Nieswandt, B., Gawa, M.A., 2002. Critical role of platelet adhesion in the initiation of atherosclerotic lesion formation. J. Exp. Med. 196(7), 887-896.

McGregor, L., Morazain, R., Renaud, S., 1980.A comparison of the effects of dietary short and long chain saturated fatty acids on platelet functions, platelet phospholipids, and blood coagulation in rats. Lab. Invest. 43(5), 438442.

McKenna, R., Bachmann, F., Miro-Quesada, M., 1977. Thromboembolism in patients with abnormally short activated thromboplastin time. Thromb. Haemost. 38 (4): 893-899.

Meade, T.W., Mellows, S., Brozovic, M., Miller, G.J., Chakrabarti, R.R., North, W.R.S.,Haines, A.P., Stirling, Y., Imeson, J.D., Thompson, S.G., 1986. Haemostatic function and ischaemic heart disease: principal results of the Northwick Park Heart Study. Lancet. 2(8506), 533537.

Miller, G.J., 1997. Dietary fatty acids and blood coagulation. Prostaglandins Leukot. Essent. Fatty Acids. 57(4-5), 389394.

Miller, G.J., Bauer, K.A., Barzegar, S., Cooper, J.A., Rosenberg, R.D., 1996. Increased activation of the haemostatic system in men at high risk of fatal coronary heart disease. Thromb. Haemost. 75(5), 767-771. 
Moertl, D., Berger, R., Hammer, A., Hutuleac, R., Koppensteiner, R., Kopp, C.W., Steiner, S., 2011.Dosedependent decrease of platelet activation and tissue factor by omega-3 polyunsaturated fatty acids in patients with advanced chronic heart failure. Thromb. Haemost. 106 (3), 457- 465.

Monkovic, D.D., Tracy, P.B., 1990. Activation of human factor V by factor Xa and thrombin. Biochemistry. 29(5), 1118-1128.

Mosesson, M.W., 2005. Fibrinogen and fibrin structure and functions. J. Thromb. Haemost. 3(8), 1894-1904.

Muakkassa, F.F., Koruda, M.J., Ramadan, F.M., Kawakami, M., Meyer, A.A., 1991. Effect of dietary fish oil on plasma thromboxane B2 and 6-keto-prostaglandin F1 alpha levels in septic rats. Arch. Surg. 126(2), 179-82.

Mutanen, M., Freese, R., 1996. Polyunsaturated fatty acids and platelet aggregation. Curr. Opin. Lipidol. 7(1), 14-19.

Nelson, G.J., Schmidt, P.C., Bartolini, G., Kelley, D.S., Kyle, D., 1997.The effect of dietary arachidonic acid on platelet function, platelet fatty acid composition, and blood coagulation in humans. Lipids. 32(4), 421-425.

Nesheim, M.E., Taswell, J.B., Mann, K.G., 1979. The contribution of bovine Factor $\mathrm{V}$ and Factor $\mathrm{Va}$ to the activity of prothrombinase. J. Biol. Chem. 254(21), 10952-10962.

Nevin, K.G., Rajamohan, T., 2004. Beneficial effects of virgin coconut oil on lipid parameters and in vitro LDL oxidation. Clin. Biochem. 37(9), 830-835.

Nevin, K.G., Rajamohan, T., 2008. Influence of virgin coconut oil on blood coagulation factors, lipid levels and LDL oxidation in cholesterol fed Sprague-Dawley rats. eSPEN. 3 (1), e1-e8.

Nossel, H.L., 1998. Relative proteolysis of the fibrinogen chain by thrombin and plasmin as a determinant of thrombosis. Nature. 291 (5811), 165-167.

Patrono, C., Ciabattoni, G., Davì, G., 1991. Thromboxanedependent platelet activation as a transducer of enhanced risk of coronary and cerebral thrombosis. Adv. Prostaglandin. Thromboxane. Leukot. Res. 21 B, 619-622.

Petroni, A., Blasevich, M., Salami, M., Servili, M., Montedoro, G.F., Galli, C.A., 1994. Phenolic antioxidant extracted from olive oil inhibits platelet aggregation andarachidonic acid metabolism in vitro. World. Rev. Nutr. Dietetics. 75,169-172.

Phang, M., Lincz, L.F., Garg, M.L., 2013.Eicosapentaenoic and docosahexaenoic acid supplementations reduce platelet aggregation and hemostatic markers differentially in men and women. J. Nutr. 143 (4), 457- 463.

Qureshi, A.A., Karpen, C.W., Qureshi, N., Papasian, C.J., Morrisonm, D.C., Folts, J.D., 2011. Tocotrienols-induced inhibition of platelet thrombus formation and platelet aggregation in stenosed canine coronary arteries. Lipids. Health. Dis. 10, 58.

Rand, M.L., Hennissen, A.A., Hornstra, G., 1988. Effects of dietary palm oil on arterial thrombosis, platelet responses and platelet membrane fluidity in rats. Lipids. 23 (11), 1019-1023.

Renaud, S., Godsey, F., Dumont, E., Thevenon, C., Ortchanian, E., Martin, J.L.,1986. Influence of long-term diet modification on platelet function and composition in moselle farmers. Am. J. Clin .Nutr. 43 (1), 136-150.

Rosing, J., Tans, G., Govers-Riemslag, J.W., Zwaal, R.F., Hemker, H.C., 1980. The role of phospholipids and factor Va in the prothrombinase complex. J. Biol. Chem. 255 (1), 274-283.

Saldeen, P., Nilsson, I.M., Saldeen, T., 1983. Increased synthesis of thromboxane B2 and 6-keto- PGF1 alphas in hand veins from patients with deep venous thrombosis. Thromb. Res. 32(5), 461-467.

Steel, M.S., Naughton, J.M., Hopkins, G.W., Sinclair, A.J., O'Dea, K., 1990. Effects of dietary fats on prostanoid production and aortic and plasma fatty acid composition in rats. Lipids. 25(11), 719-723.

Takachi, R., Kimira, M., Uesugi, S., Kudo, Y., Ouchi, K., Watanabe, S., 2004.The effect of dietary and plasma fatty acids on platelet aggregation in senior generation of Japanese women. Biofactors. 22(1-4), 205-210.

Takasaki, W., Nakagawa, A., Tanaka, Y., Nakamura, K., Shindo, H., Hayashi, Y., Yamamoto, S., 1991. Enzyme immunoassay of human plasma 11-dehydrothromboxane B2. Thromb. Res. 63(3), 331-341.

Tholstrup, T., Miller, G. M., Bysted, A., Sandstrom, B., 2003.Effect of individual dietary fatty acids on postprandial activation of blood coagulation factor VII and fibrinolysis in healthy young men. Am. J. Clin. Nutr. 77(5), 1125-1132.

Véricel, E., Januel, C., Carreras, M., Moulin, P., Lagarde, M., 2004. Diabetic patients without vascular complications display enhanced basal platelet activation and decreased antioxidant status. Diabetes. 53(4), 1046-1051.

Vilaseca, J., Salas, A., Guarner, F., Rodríguez, R., Martínez, M., Malagelada, J. R., 1990. Dietary fish oil reduces progression of chronic inflammatory lesions in a rat model of granulomatous colitis. Gut. 31(5), 539-544.

Whelan, J., Surette, M., Hardardottir, I., Lu, G., Golemboski, K.A., Larsen, E., Kinsella, J.E., 1993.Dietary arachidonate enhances tissue arachidonate levels and eicosanoid production in syrian hamsters. J. Nutr. 123(12), 21742185 .

\section{How to cite this article:}

Arunima, S., Rajamohan, T., 2016. Supplementation of virgin coconut oil compared with copra oil, olive oil and sunflower oil on thrombotic factors in rats and in vitro platelet aggregation. Int. J. Curr. Res. Biosci. Plant Biol. 3(2), 106-113. doi: http://dx.doi.org/10.20546/ijcrbp.2016.302.013 